\section{Crossing paradigms}

T t was a journey, says Dr. David Ponka, that revealed the "dissonance" between the privilege of the West and the angst of the developing world. It also managed to generate an array of arresting photos that reveal that dissonance with remarkable clarity and grace.

The selections reproduced here were taken by the Ottawa-based physician while participating in various international relief efforts, including a stint at a Médecins Sans Frontières field hospital in Chad, on the Darfur border.

A mix of medical, cultural and humanitarian photos are part of an exhibition on display until Mar. 28, 2008, at the Bruyère Gallery within the Elizabeth Bruyère Family Health Centre in Ottawa. Reprints (\$I50 to \$250) can be purchased at scohs.on.ca, with all proceeds being donated equally to Médecins Sans Frontières and the Bruyère-Panama project, which links health care staff from the clinic with remote communities in Panama. - Wayne Kondro, CMAJ

DOI:I0.1503/cmaj.080II2

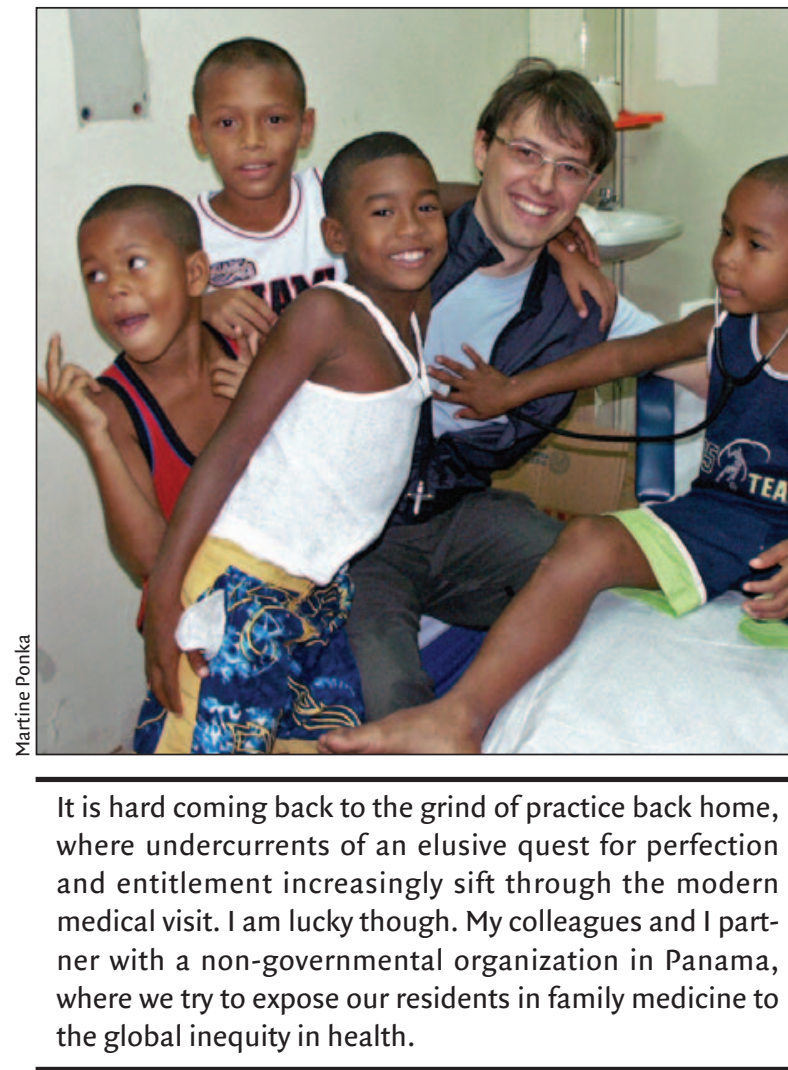

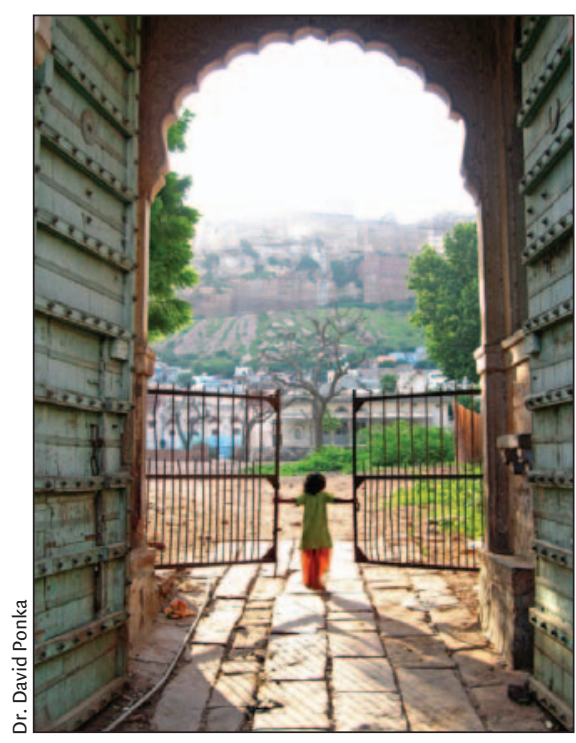

Colour is always so much more striking in the middle of a desert, whether in the Sahara or in Rajhastan. My wife and I had decided to take a trip before my stint alone with Médecins San Frontières. After days travelling by train through the desert, this scene in the ancient walled city of Jodhpur almost startled us out of our senses. 
The local doctor and I are collaborating on a toe amputation to treat a mild case of gangrene. The patient was up dancing the next week and didn't know how to thank us. Even when you could do nothing, patients and families were beyond grateful for our efforts.

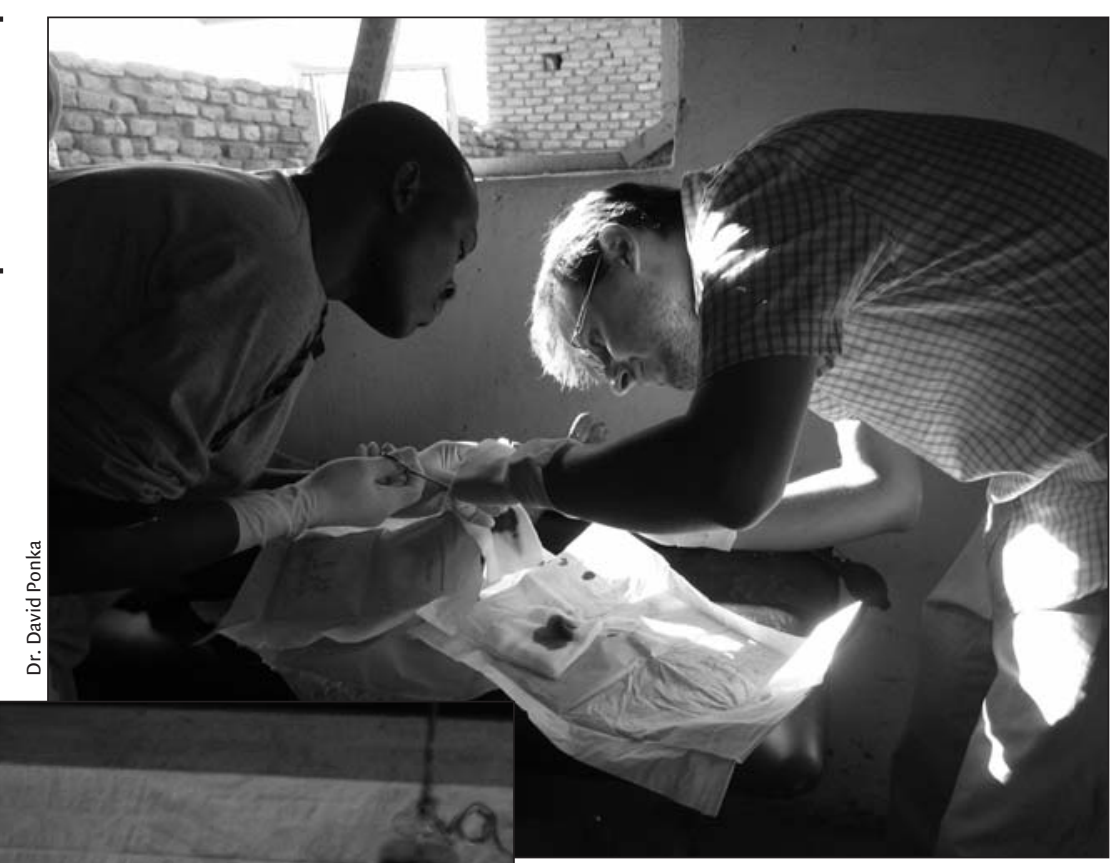

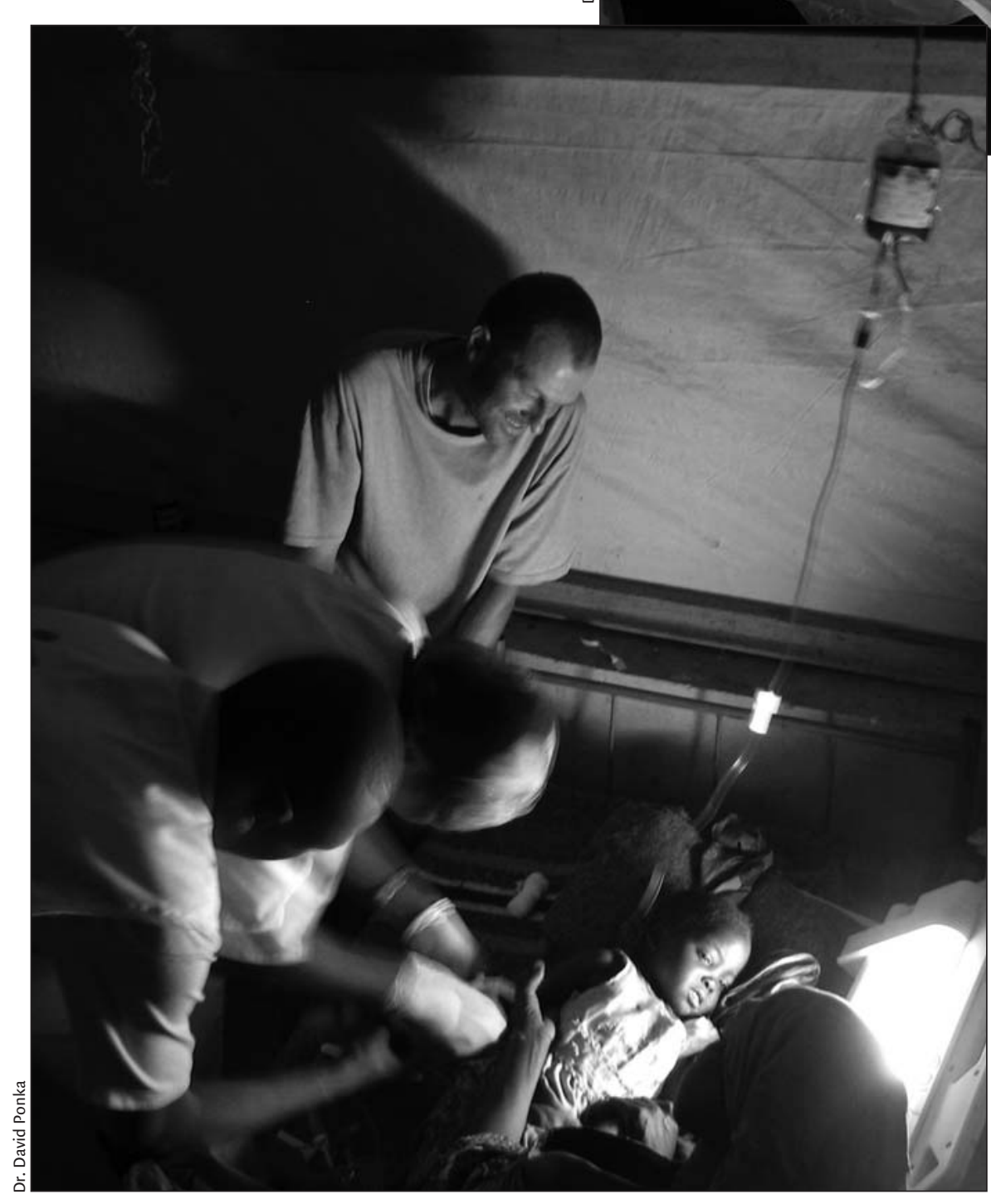

We saw 100 cases of falciparum malaria every week. This girl had hemolytic anemia from the disease and though I could only guess her hemoglobin, it was critical. No one would give her blood, including her family, as it it a completely foreign concept in this isolated region. Finally, our logistician Nicolas (seen standing in the picture) donated 3 units. She survived.

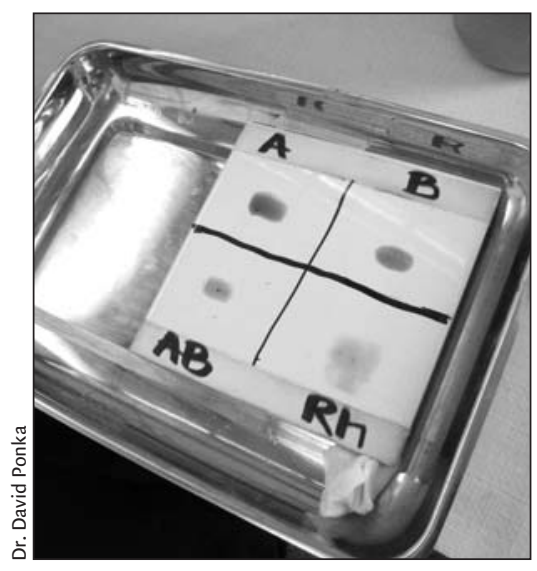

This is how I would test for blood groups and compatibility, praying I would not make a mistake. No one died on account of an error, but I will never take transfusion for granted again. 